\title{
Eficiência de genótipos de feijoeiro em resposta à adubação nitrogenada ${ }^{1}$
}

\author{
Fabricio Henrique Moreira Salgado ${ }^{2}$, Joedna Silva ${ }^{2}$, Taynar Coelho de Oliveira ${ }^{2}$,
} Hélio Bandeira Barros ${ }^{2}$, Nathan Gonçalves dos Passos², Rodrigo Ribeiro Fidelis ${ }^{2}$

\begin{abstract}
Efficiency of common bean

genotypes in response to nitrogen fertilization

Bean genotypes react differently to available nitrogen. This research aimed at selecting bean genotypes, concerning their efficiency and reaction to nitrogen absorption. The treatments consisted of twelve genotypes cultivated in two different environments, one simulating a low nitrogen level $\left(20 \mathrm{~kg} \mathrm{ha}^{-1}\right)$ and the other a high nitrogen level $\left(120 \mathrm{~kg} \mathrm{ha}^{-1}\right)$. The experimental design was randomized complete bocks, with four replications. The grain yield was evaluated, for classifying cultivars in relation to nitrogen use efficiency and response to application, as well as chlorophyll rates, by using a chlorophyllometer. The BRS-Grafite and Princesa genotypes were considered efficient, regarding the nitrogen fertilization, and responsive to the nitrogen application. Bean plants supplied with adequate nitrogen rates presented higher cholorophyll ( $a, b$ and total) levels.
\end{abstract}

KEY-WORDS: Phaseolus vulgaris L.; mineral stress; nitrogen fertilization.

\section{INTRODUÇÃO}

O feijão (Phaseolus vulgaris L.) é um dos mais importantes constituintes da dieta brasileira, por ser excelente fonte proteica, fornecer ao organismo carboidratos, vitaminas, fibras, ferro e zinco (Thung \& Oliveira 1998, Borém \& Carneiro 2006) e apresentar grande importância econômica, em razão da grande quantidade de mão de obra demandada no seu cultivo. Borém \& Carneiro (2006) estimam que, só em Minas Gerais, sejam empregadas cerca de 7 milhões de pessoas por ciclo da cultura.

Apesar de sua importância no Brasil, a produtividade nacional é baixa, variando de $700 \mathrm{~kg} \mathrm{ha}^{-1}$ (Borém \& Carneiro 2006) a $842 \mathrm{~kg} \mathrm{ha}^{-1}$ (Conab 2011), sendo a adubação nitrogenada um dos fatores

\section{RESUMO}

Genótipos de feijão respondem ao nitrogênio de forma diferenciada, de acordo com a disponibilidade deste nutriente. Assim, objetivou-se, com este trabalho, selecionar genótipos de feijoeiro, quanto à eficiência e resposta à absorção de nitrogênio. Os tratamentos envolveram doze genótipos cultivados em dois ambientes distintos, um simulando baixo nível $\left(20 \mathrm{~kg} \mathrm{ha}^{-1}\right) \mathrm{e}$ outro alto nível $\left(120 \mathrm{~kg} \mathrm{ha}^{-1}\right)$ de nitrogênio. O delineamento experimental utilizado foi o de blocos completos casualizados, com quatro repetições. Foram avaliados a produtividade de grãos, para classificação das cultivares quanto à eficiência no uso e resposta à aplicação de nitrogênio, e índices de clorofila, com o uso de clorofilômetro. Os genótipos de feijão BRS-Grafite e Princesa foram eficientes, quanto à utilização da adubação nitrogenada, e responsivos à aplicação de nitrogênio. Plantas de feijoeiro conduzidas com adequado suprimento de nitrogênio apresentaram maiores índices de clorofila ( $a, b$ e total).

PALAVRAS-CHAVE: Phaseolus vulgaris L.; estresse mineral; adubação nitrogenada.

limitantes (Silva \& Silveira 2000, Fageria \& Baligar 2005, Sant'Ana et al. 2010).

O nitrogênio tem como reservatório a atmosfera terrestre, com $78 \%$ de sua composição. Porém, este é um gás inerte $\left(\mathrm{N}_{2}\right)$, que necessita ser combinado com outros elementos, como o hidrogênio, que é extraído do gás natural, para produzir fertilizantes nitrogenados (Lopes et al. 2007).

É um nutriente que se perde facilmente, em função de diversos processos, como a lixiviação, volatilização e desnitrificação (Fageria \& Baligar 2005, Sant'Ana et al. 2010). Devido a estas perdas, o manejo adequado tem como propósito maximizar a eficiência do seu uso pelas culturas (Amado et al. 2000). Para tanto, tem-se buscado reduzir sua perda no solo e melhorar sua absorção pelas plantas (Bredemeier \& Mundstock 2000), levando-se em consideração a genética do material.

1. Trabalho recebido em ago./2011 e aceito para publicação em ago./2012 (nº registro: PAT 15413).

2. Universidade Federal do Tocantins (UFT), Campus Universitário de Gurupi, Gurupi, TO, Brasil. E-mails: fabriciogpi@hotmail.com, joedna@mail.uft.edu.br, taynar@mail.uft.edu.br, barroshb@mail.uft.edu.br, nathan_passos_@hotmail.com, fidelisrr@mail.uft.edu.br. 
Furlani et al. (1986) relataram que diferentes espécies vegetais apresentam capacidade similar na absorção de um determinado nutriente, podendo ocorrer grandes diferenças entre elas, na produção de biomassa resultante de diferenças na eficiência de utilização. No caso específico do feijoeiro, os relatos são escassos, antigos e restritos a genótipos que não são mais comercialmente usuais (Furtini et al. 2006). Desta forma, objetivou-se, com este trabalho, avaliar genótipos de feijoeiro, quanto à eficiência e resposta à absorção de nitrogênio.

\section{MATERIAL E MÉTODOS}

Foram conduzidos dois experimentos, na Estação Experimental de Pesquisa da Universidade Federal do Tocantins (UFT), pertencente ao Campus Universitário de Gurupi (TO) (11\%43'45' S, 49 04'07'W e altitude de $280 \mathrm{~m}$ ). A caracterização climática do local é Aw Cerrado ou Savana tropical, segundo Köppen-Geiger (Peel et al. 2007). O solo foi classificado como Latossolo Vermelho-Amarelo distrófico (LVAd), textura média (Embrapa 2006).

A análise química e granulométrica do solo, na camada de $0-20,0 \mathrm{~cm}$, revelou os seguintes resultados: $\mathrm{P}\left(\right.$ Mehlich-1) $=1,1 \mathrm{mg} \mathrm{dm}^{-3} ; \mathrm{MO}=2,0 \%$; $\mathrm{pH} \mathrm{em} \mathrm{CaCl}_{2}=4,6 ; \mathrm{Ca}+\mathrm{Mg}=5 \mathrm{cmol}_{\mathrm{c}} \mathrm{dm}^{-3} ; \mathrm{Ca}=$ $3,6 \mathrm{cmol} \mathrm{dm}_{\mathrm{c}}^{-3} ; \mathrm{Mg}=1,4 \mathrm{cmol}_{\mathrm{c}} \mathrm{dm}^{-3} ; \mathrm{Al}=0,0 \mathrm{cmol}_{\mathrm{c}} \mathrm{dm}^{-3}$; $\mathrm{H}+\mathrm{Al} \stackrel{\mathrm{c}}{=} 4,7 \mathrm{cmol}_{\mathrm{c}} \mathrm{dm}^{-3} ; \mathrm{K}^{\mathrm{c}}=0,1 \mathrm{cmol}_{\mathrm{c}} \mathrm{dm}^{-3} ; \mathrm{SB}=$ $2,18 \mathrm{cmol}_{\mathrm{c}} \mathrm{dm}^{-3} ; \mathrm{V}=52,3 \%$; areia $=542,4 \mathrm{~g} \mathrm{~kg}^{-1}$; silte $=54,9 \mathrm{~g} \mathrm{~kg}^{-1}$; e argila $=402,7 \mathrm{~g} \mathrm{~kg}^{-1}$, não havendo necessidade de realização de calagem.

Foram estudados, em dois experimentos, simulando alto e baixo teor de nitrogênio, doze genótipos de feijoeiro (BRS-Grafite, IAC-Carioca Eté, IAC-Una, Safira, BRS-Marfim, CNFC 10406, Princesa, IAC-Centauro, IPR-Saracura, IPR-Colibri, IAC-Diplomata e BRS-Esplendor) de diferentes instituições. Cada experimento foi conduzido utilizando-se delineamento em blocos completos ao acaso, com quatro repetições, totalizando 48 parcelas. A parcela experimental foi constituída por quatro linhas de 4,0 m de comprimento, espaçadas em $0,45 \mathrm{~m}$. A semeadura foi realizada no dia 12 de junho de 2010 , visando-se à obtenção de estande final com 12 plantas por metro. A área útil $\left(2,7 \mathrm{~m}^{2}\right)$ utilizada constou de duas linhas centrais, desprezando-se $0,5 \mathrm{~m}$ em cada extremidade.

Para o controle de doenças e pragas do solo, as sementes foram tratadas com fungicida perten- cente aos grupos químicos Benzimidazol e Dimetilditiocarbamato $\left(45+105\right.$ g i.a. $100 \mathrm{~kg}$ sementes $\left.^{-1}\right)$ e inseticida pertencente ao grupo químico Pirazol $\left(50\right.$ g i.a. $100 \mathrm{~kg}$ sementes $\left.^{-1}\right)$. Durante a condução do experimento, a área foi mantida limpa, com a aplicação de herbicida pertencente ao grupo químico Oxima ciclohexanodiona e capina manual antes do florescimento (R6). O manejo de pragas foi realizado com a aplicação de inseticida pertencente ao grupo químico Piretroide ( 4 g i.a. ha ${ }^{-1}$ ), aos 31 dias após a emergência (DAE), e ao grupo químico Organofosforado (500 g i.a. ha $\mathrm{ha}^{-1}$ ), aos 46 DAE.

A irrigação foi feita de acordo com as necessidades da cultura, segundo recomendação para Santo Antônio de Goiás (GO) (Curi \& Campelo Júnior 2001). Utilizou-se sistema de aspersão convencional, com turno de rega de dois dias, com um período de funcionamento de duas horas. A vazão dos aspersores utilizados, com pressão na base de $20 \mathrm{mca}$, propiciou lâmina d'água de 5,2 $\mathrm{mm}_{\text {hora }}{ }^{-1}$.

A adubação de semeadura foi realizada com base na análise do solo e recomendações para a cultura, aplicando-se, no sulco de semeadura, $120 \mathrm{~kg} \mathrm{ha}^{-1} \mathrm{de}_{2} \mathrm{O}_{5}$, tendo, como fonte, o superfosfato simples amoniado com $3 \%$ de nitrogênio, e $50 \mathrm{~kg} \mathrm{ha}^{-1} \mathrm{de}_{2} \mathrm{O}$, tendo, como fonte, o cloreto de potássio, para os dois experimentos.

Com relação à adubação nitrogenada realizada no primeiro experimento, que simulou ambiente com estresse de $\mathrm{N}$, foram aplicados $20 \mathrm{~kg} \mathrm{ha}^{-1}$ de $\mathrm{N}$ na semeadura, sendo o nutriente proveniente da adubação fosfatada. No segundo experimento, que simulou ambiente sem estresse de $\mathrm{N}$, foram aplicados $120 \mathrm{~kg} \mathrm{ha}^{-1}$ de $\mathrm{N}$, sendo $20 \mathrm{~kg} \mathrm{ha}^{-1}$ aplicados na semeadura, provenientes da adubação fosfatada, e $100 \mathrm{~kg} \mathrm{ha}^{-1}$, na forma de ureia, aplicados em cobertura e parcelados em duas vezes, sendo a primeira aos 15 DAE e a segunda aos 30 DAE (Rosolem \& Marubayashi 1994).

Para diferenciação dos genótipos, quanto à eficiência de utilização do N, foi adotada metodologia proposta por Fageria \& Kluthcouski (1980), que sugere a classificação das cultivares quanto à eficiência no uso e resposta à aplicação de nitrogênio. Desta forma, a utilização do nutriente foi definida pela média de produtividade de grãos em baixo nível de nitrogênio, oriunda do experimento que simulou o estresse. A resposta à utilização do nutriente foi obtida pela diferença entre a produtividade de grãos, nos dois níveis (ideal e baixo N), dividida pela diferença entre as doses: $\alpha=(\mathrm{PNN}-\mathrm{PBN}) / \mathrm{DEN}$, onde 
$\alpha=$ índice de resposta ao nutriente; $\mathrm{PNN}=$ produção com nível ideal de nutriente; $\mathrm{PBN}=$ produção com baixo nível do nutriente; e DEN = diferença entre as doses $\left(\mathrm{kg} \mathrm{ha}^{-1}\right)$.

Foi utilizada uma representação gráfica, no plano cartesiano, para classificar as cultivares (Fageria \& Kluthcouski 1980). No eixo das abscissas (x), encontra-se a eficiência na utilização do nitrogênio, e, no eixo das ordenadas (y), a resposta à sua utilização. O ponto de origem dos eixos é a eficiência média e a resposta média das cultivares. No primeiro quadrante, são representadas as cultivares eficientes e responsivas (ER), no segundo as não eficientes e responsivas (NER), no terceiro as não eficientes e não responsivas (NENR) e, no quarto, as eficientes e não responsivas (ENR).

Foram quantificados os índices de clorofila $(a, b$ e total $=a+b)$, expressos em unidade denominada Índice de Clorofila Falker (ICF), resultante de unidades adimensionais (Falker 2008) existentes nas folhas, utilizando-se método indireto, por meio de leitura efetuada em aparelho clorofilômetro ClorofiLOG ${ }^{\circledR}$, modelo CFL 1030, que utiliza emissores em três comprimentos de onda: dois dentro da banda do vermelho, próximos aos picos de cada tipo de clorofila (635 $\mathrm{nm}$ e $660 \mathrm{~nm})$, e outro no infravermelho próximo $(880 \mathrm{~nm})$. Assim, as leituras foram realizadas durante o florescimento pleno (R6), sempre na primeira folha completamente expandida (do topo do dossel para a base) e exposta à radiação solar.
Foram realizadas três leituras por planta, em três plantas por parcela.

Os dados experimentais foram submetidos a análises individuais e, posteriormente, à análise conjunta de variância, sob condições de homogeneidade das variâncias residuais, com aplicação do teste F. Para as comparações entre as médias dos tratamentos, foi utilizado o teste Tukey, a 5\%. Utilizou-se, para estas análises, o programa estatístico Sisvar (Ferreira 2003).

\section{RESULTADOS E DISCUSSÃO}

Com relação aos índices de clorofila $(a, b$ e total) (Tabela 1), observou-se que não houve interação entres os fatores genótipos e ambientes, ou seja, a dose de nitrogênio não influenciou, de forma diferenciada, os genótipos estudados. $\mathrm{O}$ ambiente sem estresse de $\mathrm{N}$ propiciou maiores médias de clorofila nas folhas de feijoeiro. Observou-se, para a clorofila $a$, que o maior índice foi obtido pelo genótipo Safira, o qual, entretanto, não diferiu dos que obtiveram índice acima de 33,25. Quanto à clorofila $b$, destacaram-se os genótipos Princesa e Safira, os quais, contudo, não diferiram dos que obtiveram média superior a 11,63. Para o índice de clorofila total, apenas o genótipo Safira diferiu significativamente do BRS-Marfim.

Com relação aos índices de clorofila, não observou-se resultado conclusivo da relação destes com a eficiência e resposta na utilização de N, como

Tabela 1. Médias de Índices Falker de Clorofila ( $a, b$ e total) de 12 genótipos de feijoeiro, em função do estresse em presença ou ausência de nitrogênio (Gurupi, TO, 2010).

\begin{tabular}{|c|c|c|c|c|c|c|c|c|c|}
\hline \multirow{3}{*}{ Genótipo } & \multicolumn{2}{|c|}{ Estresse nitrogênio } & \multirow{2}{*}{ Média } & \multicolumn{2}{|c|}{ Estresse nitrogênio } & \multirow{2}{*}{ Média } & \multicolumn{2}{|c|}{ Estresse nitrogênio } & \multirow{2}{*}{ Média } \\
\hline & Com & Sem & & Com & Sem & & Com & Sem & \\
\hline & \multicolumn{3}{|c|}{ Clorofila $a$} & \multicolumn{3}{|c|}{ Clorofila $b$} & \multicolumn{3}{|c|}{ Clorofila total } \\
\hline BRS-Esplendor & 30,25 & 34,25 & $32,25 \mathrm{bc}$ & 9,00 & 11,75 & $10,38 \mathrm{~cd}$ & 39,62 & 45,49 & $42,56 \mathrm{ab}$ \\
\hline BRS-Grafite & 31,50 & 36,25 & $33,88 \mathrm{abc}$ & 10,75 & 14,00 & $12,38 \mathrm{abc}$ & 42,37 & 50,51 & $46,44 \mathrm{ab}$ \\
\hline BRS-Marfim & 32,25 & 34,75 & $33,50 \mathrm{abc}$ & 10,75 & 12,50 & $11,63 \mathrm{abcd}$ & 32,93 & 47,04 & $39,98 \mathrm{~b}$ \\
\hline CNFC-10406 & 31,75 & 36,25 & $34,00 \mathrm{abc}$ & 10,50 & 14,00 & $12,25 \mathrm{abc}$ & 42,26 & 50,25 & $46,26 \mathrm{ab}$ \\
\hline IAC-Carioca Eté & 30,00 & 34,50 & $32,25 \mathrm{bc}$ & 9,50 & 12,00 & $10,75 \mathrm{bcd}$ & 39,38 & 46,49 & $42,93 \mathrm{ab}$ \\
\hline IAC-Centauro & 30,50 & 34,50 & $32,50 \mathrm{bc}$ & 9,75 & 11,75 & $10,75 \mathrm{bcd}$ & 40,15 & 46,45 & $43,30 \mathrm{ab}$ \\
\hline IAC-Diplomata & 30,75 & 36,00 & $33,38 \mathrm{abc}$ & 11,75 & 13,25 & $12,50 \mathrm{ab}$ & 44,93 & 49,09 & $47,01 \mathrm{ab}$ \\
\hline IAC-Una & 29,25 & 34,75 & $31,88 \mathrm{c}$ & 8,25 & 11,75 & $10,00 \mathrm{~d}$ & 37,38 & 46,05 & $41,72 \mathrm{ab}$ \\
\hline IPR-Colibri & 30,75 & 35,75 & $33,25 \mathrm{abc}$ & 10,25 & 13,50 & $11,88 \mathrm{abcd}$ & 40,98 & 49,12 & $45,05 \mathrm{ab}$ \\
\hline IPR-Saracura & 32,50 & 37,00 & $34,75 \mathrm{abc}$ & 11,00 & 14,25 & $12,63 \mathrm{ab}$ & 43,61 & 51,13 & $47,37 \mathrm{ab}$ \\
\hline Princesa & 34,50 & 35,50 & $35,00 \mathrm{ab}$ & 13,00 & 13,50 & $13,25 \mathrm{a}$ & 47,44 & 48,26 & $47,85 \mathrm{ab}$ \\
\hline Safira & 34,25 & 37,50 & $35,88 \mathrm{a}$ & 11,75 & 14,75 & $13,25 \mathrm{a}$ & 46,22 & 52,20 & $49,21 \mathrm{a}$ \\
\hline Média & $31,52 \mathrm{~B}$ & $35,56 \mathrm{~A}$ & & $10,52 \mathrm{~B}$ & $13,06 \mathrm{~A}$ & & $41,44 \mathrm{~B}$ & $58,51 \mathrm{~A}$ & - \\
\hline $\mathrm{CV}(\%)$ & & 5,24 & & & 10,21 & & & & \\
\hline
\end{tabular}

Médias seguidas da mesma letra minúscula, na coluna, e maiúscula, na linha, não diferem entre si pelo teste Tukey, a 5\%. 
pôde ser observado para as cultivares Safira e Princesa, que obtiveram os maiores índices de clorofila $a, b$ e total, sendo estatisticamente iguais, porém classificados como não eficiente e não responsivo (Safira) e eficiente e responsivo (Princesa).

A clorofila é o pigmento responsável pela captação da energia solar, atuando na oxidação da água e, consequentemente, na liberação do oxigênio e redução do dióxido de carbono, para a formação de cadeias carbônicas, principalmente açúcar (Taiz \& Zeiger 2009). O índice de clorofila nas folhas apresenta alta correlação com o teor de $\mathrm{N}$ da planta e, desta forma, a leitura com clorofilômetro é um método eficiente para a avaliação do estado nutricional das plantas (Argenta et al. 2001, Barbieri Júnior 2009).

Com relação à produtividade de grãos (Tabela 2), a interação influenciou de forma diferenciada os genótipos analisados. Sete dos dozes genótipos avaliados responderam de forma positiva ao acréscimo do nutriente nitrogênio (BRS-Grafite, IAC-Centauro, IPR-Colibri, IAC-Diplomata, IAC-Una, Princesa e a linhagem CNFC-10406). A cultivar IAC-Carioca Eté respondeu de forma negativa a este acréscimo, sendo mais produtiva em ambiente sob estresse nutricional por $\mathrm{N}$, por ser, provavelmente, mais rústica que as demais cultivares. Resposta negativa à aplicação de nitrogênio em feijão também foi obtida por Furtini et al. (2006), com a linhagem MA-I-2.5, os quais levantaram a hipótese de maior desenvolvimento vegetativo em presença de $\mathrm{N}$, em detrimento da fase reprodutiva.
Em ambiente com estresse de nitrogênio, a produtividade ficou acima da média nacional, que é de $842 \mathrm{~kg} \mathrm{ha}^{-1}$ (Conab 2011), para nove genótipos (Tabela 2). Observou-se que a cultivar IAC-Carioca Eté foi a que apresentou maior média de produtividade $\left(2245,8 \mathrm{~kg} \mathrm{ha}^{-1}\right)$, entretanto, não diferenciou-se das cultivares Princesa, IPR-Saracura e BRS-Grafite. Dorcinvil et al. (2010) observaram, analisando 36 genótipos de feijoeiro, que a falta de nitrogênio foi limitante, entretanto, mesmo com o estresse de nitrogênio, dependendo da época de plantio e do genótipo utilizado, a produdtividade média atingiu mais de $2.000 \mathrm{~kg} \mathrm{ha}^{-1}$.

No ambiente sem estresse de $\mathrm{N}$, a média de produtividade variou entre $1.000 \mathrm{~kg} \mathrm{ha}^{-1} \mathrm{e}$ $3.135 \mathrm{~kg} \mathrm{ha}^{-1}$, sendo que a cultivar Princesa apresentou maior produtividade $\left(3.133,4 \mathrm{~kg} \mathrm{ha}^{-1}\right)$, apesar de não diferir das cultivares IAC-Centauro, BRS-Grafite, IAC-Diplomata e IAC-Colibri (Tabela 2).

Oito genótipos apresentaram produtividade superior à média do Estado de Minas Gerais (1.424 kg ha-1), que é o segundo maior produtor desta cultura (Borém \& Carneiro 2006, Conab 2011). Salgado et al. (2011) observaram, no Estado do Tocantins (Gurupi), produtividade de grãos acima de $1.400 \mathrm{~kg} \mathrm{ha}^{-1}$, para todos os genótipos avaliados, com destaque para a cultivar Uirapuru $\left(3.132,86 \mathrm{~kg} \mathrm{ha}^{-1}\right)$, com dose de nitrogênio de $80 \mathrm{~kg} \mathrm{ha}^{-1}$, corroborando os valores obtidos neste trabalho. Franco et al. (2008) verificaram influência positiva do aumento da dose de nitrogênio no rendimento de grãos de feijoeiro,

Tabela 2. Produtividade, média de eficiência e índice de resposta de 12 genótipos de feijoeiro ao nitrogênio (Gurupi, TO, 2010).

\begin{tabular}{|c|c|c|c|c|c|c|}
\hline \multirow{4}{*}{ Genótipo } & \multicolumn{3}{|c|}{ Produtividade } & \multirow{3}{*}{ Eficiência } & \multirow{3}{*}{$\begin{array}{l}\text { Diferença de } \\
\text { produtividade }\end{array}$} & \multirow{4}{*}{$\begin{array}{l}\text { Índice } \\
\text { resposta }\end{array}$} \\
\hline & \multicolumn{2}{|c|}{ Estresse nitrogênio } & \multirow{2}{*}{ Média } & & & \\
\hline & Com & Sem & & & & \\
\hline & & & $-\mathrm{kg} \mathrm{ha}^{-1}$ & & & \\
\hline BRS-Esplendor & $1.101,4$ bcA & $1.422,8 \mathrm{cdA}$ & $1.262,1$ & $1.101,4$ & 321,35 & 3,2 \\
\hline BRS-Grafite & $1.182,3 \mathrm{abcB}$ & $2.327,6 \mathrm{abcA}$ & $1.754,9$ & $1.182,3$ & $1.145,27$ & 11,5 \\
\hline BRS-Marfim & $570,8 \mathrm{cA}$ & $1.060,2 \mathrm{dA}$ & 815,5 & 570,8 & 489,45 & 4,9 \\
\hline CNFC-10406 & $876,3 \mathrm{bcB}$ & $1.737,2 \mathrm{bcdA}$ & $1.306,8$ & 876,3 & 860,97 & 8,6 \\
\hline IAC-Carioca Eté & $2.245,8 \mathrm{aA}$ & $1.254,9 \mathrm{cdB}$ & $1.750,4$ & $2.245,8$ & $-990,94$ & $-9,9$ \\
\hline IAC-Centauro & $952,1 \mathrm{bcB}$ & $2.562,9 \mathrm{abA}$ & $1.757,5$ & 952,1 & $1.601,87$ & 16,1 \\
\hline IAC-Diplomata & $825,7 \mathrm{bcB}$ & $2.284,5 \mathrm{abcA}$ & $1.555,1$ & 825,7 & $1.458,83$ & 14,6 \\
\hline IAC-Uma & 841,4 bcB & $1.859,2 \mathrm{bcdA}$ & $1.350,3$ & 841,4 & $1.017,75$ & 10,2 \\
\hline IPR-Colibri & $1.018,1 \mathrm{bcB}$ & $2.253,7 \mathrm{abcA}$ & $1.635,9$ & $1.018,1$ & $1.235,58$ & 12,4 \\
\hline IPR-Saracura & $1.553,1 \mathrm{abcA}$ & $1.794,5 \mathrm{bcdA}$ & $1.673,8$ & $1.553,1$ & 241,39 & 2,4 \\
\hline Princesa & $1.699,8 \mathrm{abB}$ & $3.133,4 \mathrm{aA}$ & $2.416,6$ & $1.699,8$ & $1.433,61$ & 14,3 \\
\hline Safira & $1.061,7 \mathrm{bcA}$ & $1.348,0 \mathrm{cdA}$ & $1.204,9$ & $1.061,7$ & 286,32 & 2,9 \\
\hline Média & $1.160,7$ & $1.919,9$ & & $1.160,7$ & - & 7,6 \\
\hline CV (\%) & 30,30 & & & & & \\
\hline
\end{tabular}


em plantio direto. Dorcinvil et al. (2010) também obtiveram produtividade acima de $3.000 \mathrm{~kg} \mathrm{ha}^{-1}$, com o acréscimo de nitrogênio.

Com base na metodologia específica para estresse mineral, identificou-se, como eficientes no uso de nitrogênio, as cultivares de feijoeiro Princesa, BRS-Grafite, IPR-Saracura e IAC-Carioca Eté, pois apresentaram as maiores médias de produtividade de grãos em ambiente de estresse de N, e, portanto, estão representadas no primeiro e quarto quadrantes da Figura 1.

Epstein \& Bloom (2004) concluíram que a eficiência no uso do nutriente é resultado da soma de dois fatores: eficiência na utilização de nutrientes (produtividade por unidade de nutriente absorvido) e eficiência de absorção de nutriente (quantidade de nutriente absorvido por quantidade de nutriente aplicado). Eficiência no uso de nitrogênio, em genótipos de feijoeiro, também foi observada em ambiente de várzea, por Santos \& Fageria (2007). Fageria (1998) constatou, em cultivares de feijão, eficiência quanto ao uso de fósforo, em trabalho realizado em vasos. Sant'Ana et al. (2011), trabalhando com cultivares de feijão, observaram influência da dose na eficiência dos genótipos estudados, constatando que quanto maior a dose, menor a eficiência na utilização do nutriente.

Quanto à resposta à aplicação de N, os genótipos CNFC-10460, IAC-Una, IPR-Colibri, IAC-Diplomata, IAC-Centauro, BRS-Grafite e Princesa foram considerados responsivos, sendo representados no primeiro e segundo quadrantes (Figura 1). Genóti-

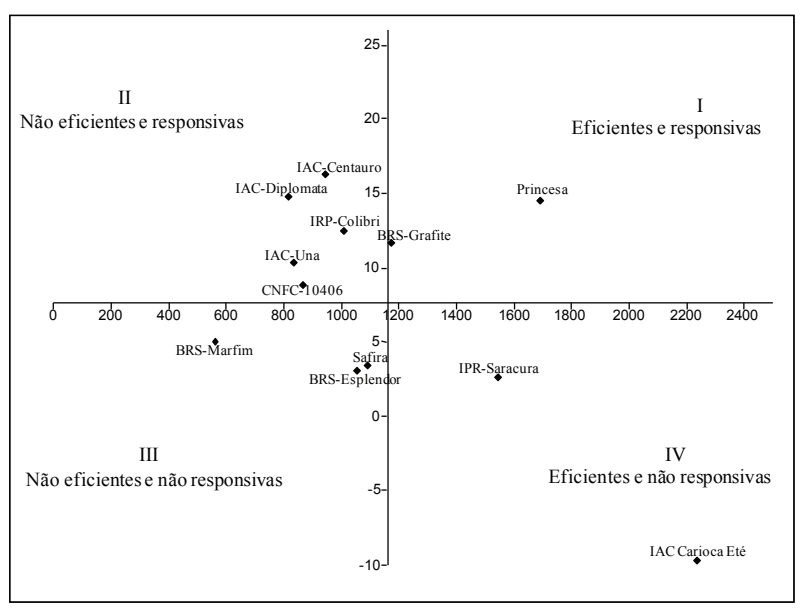

Figura 1. Eficiência no uso e resposta à aplicação de nitrogênio em genótipos de feijão, segundo metodologia de Fageria \& Kluthcouski (1980). pos que apresentam alto índice de resposta são de interesse, pois respondem ao incremento do nitrogênio, quando se promove a melhoria do ambiente. Estes genótipos apresentaram valor de índice de resposta acima de 8 (Tabela 1). A cultivar IAC-Centauro foi a que obteve maior índice de resposta $(16,1)$, ou seja, acréscimo de 16,1 kg de grãos, para cada kg de $\mathrm{N}$ aplicado. Procópio et al. (2004), estudando a eficiência na absorção de nitrogênio, em diferentes espécies vegetais, constataram diferenças entre as espécies estudadas e, ainda, diferença numérica na absorção, em especial para a cultura do feijão, resultados similares aos obtidos neste trabalho.

As cultivares BRS-Grafite e Princesa, além de terem sido consideradas responsivas, também foram apontadas como as mais eficazes em utilizar o nitrogênio, mesmo em concentrações moderadamente baixas, demonstrando sua possível adaptação, tanto a ambientes com deficiência como àqueles cujos níveis de disponibilidade de $\mathrm{N}$ são ideais (primeiro quadrante da Figura 1). Fageria (1998) também observou cultivares eficientes e responsivas ao elemento fósforo.

Os genótipos IAC-Centauro, IAC-Diplomata, IPR-Colibri, IAC-Una e CNFC-10406 foram classificados como não eficientes e responsivos (segundo quadrante da Figura 1), por terem produzido abaixo da média dos genótipos, sob ambiente de baixa dose de nitrogênio, no entanto, quando cultivados em ambiente com alta dose de N, produziram acima da média. Genótipos do grupo não eficientes e responsivos são indicados para produtores que dispõem de nível tecnológico elevado, por responderem à melhoria do ambiente (Fidelis et al. 2012).

As cultivares BRS-Marfim, BRS-Esplendor e Safira, por terem apresentado baixo rendimento de grãos, em ambiente com estresse de $\mathrm{N}$ (inferior à média dos genótipos, ou seja, 1.160,7 $\left.\mathrm{kg} \mathrm{ha}^{-1}\right)$, e, também, baixos índices de resposta à aplicação de $\mathrm{N}$ (inferior a 6,7), foram classificadas como não eficientes e não responsivas (terceiro quadrante da Figura 1). De acordo com a metodologia utilizada neste trabalho, cultivares classificadas como não eficientes e não responsivas não são recomendadas para semeadura em propriedades agrícolas, nem mesmo para aquelas que utilizam baixo nível tecnológico. Fageria (1998), trabalhando com o elemento fósforo, também identificou genótipos de feijão não eficientes e não responsivos.

No quadrante das cultivares eficientes e não responsivas, situaram-se a IPR-Saracura e IAC- 
-Carioca Eté (quarto quadrante da Figura 1), as quais produziram acima da média, em ambiente com baixa dose de N. Apesar de terem apresentado médias de produtividade de grãos acima da média geral, em ambiente sem estresse de N (1.160,7 $\left.\mathrm{kg} \mathrm{ha}^{-1}\right)$, alcançaram valores de índice de resposta menores que a média geral $(7,6)$. Isto evidencia a falta de resposta à melhoria do ambiente, com o incremento do nutriente.

Cultivares do grupo eficientes e não responsivas são recomendadas para o cultivo em propriedades que adotam baixo nível tecnológico. Esta capacidade de produzir satisfatoriamente, mesmo sob condições de estresse, ou seja, com baixa adubação nitrogenada, também pode estar relacionada à capacidade de determinados genótipos de feijão apresentarem maior capacidade de nodulação e eficiência na fixação biológica de nitrogênio (FBN), o que indica um provável potencial destes genótipos para serem incorporados a programas de melhoramento vegetal, para a FBN.

São escassos, na literatura, trabalhos envolvendo genótipos de feijão cultivados em sistema de terras altas considerados eficientes e responsivos, quanto ao uso de nitrogênio. Entretanto, a utilização da metodologia proposta por Fageria \& Kluthcouski (1980), específica para estresse mineral, foi adequada, pois identificou genótipos eficientes quanto ao uso do nitrogênio e responsivos à sua aplicação.

Quanto à eficiência na utilização de nitrogênio, observou-se que a cultivar IAC-Centauro obteve o maior índice de resposta (aumento de 16,1 $\mathrm{kg} \mathrm{ha}^{-1}$, para cada kg de nitrogênio aplicado), alcançando o maior aumento de produtividade $\left(1.601,87 \mathrm{~kg} \mathrm{ha}^{-1}\right)$, com o incremento de nitrogênio, e baixos índices de clorofila ( $a, b$ e total) (Tabelas 1 e 2 ), sendo classificada como não eficiente e responsiva (segundo quadrante da Figura 1).

A cultivar Princesa, classificada como eficiente e responsiva (primeiro quadrante da Figura 1), obteve um dos maiores índices de clorofila ( $a, b$ e total) (Tabelas 1 e 2), entretanto, apresentou índice de resposta de 14,3, valor menor que o da cultivar IAC-Centauro, que atingiu o maior índice de resposta $(16,1)$.

Silva et al. (2007) constataram que os índices obtidos pelo clorofilômetro se relacionaram com as doses de $\mathrm{N}$ aplicadas, porém, não havendo relação entre o estado nutricional, na fase vegetativa das plantas, e a produtividade de grãos.

\section{CONCLUSÕES}

1. Os genótipos de feijão BRS-Grafite e Princesa mostraram-se eficientes, quanto à utilização da adubação nitrogenada, e responsivos à aplicação de nitrogênio.

2. Ambientes sem estresse por nitrogênio proporcionaram os maiores índices de clorofila ( $a, b$ e total), em folhas de feijoeiro.

\section{REFERÊNCIAS}

AMADO, T. J. C.; MIELNIZUK, J.; FERNÁNDEZ, S. B. V. Leguminosas e adubação mineral como fontes de nitrogênio para o milho em sistemas de preparo do solo. Revista Brasileira de Ciência do Solo, Viçosa, v. 24, n. 1, p. 179-189, 2000.

ARGENTA, G.; SILVA, P. R. F. da; BORTOLINI, C. G. Clorofila na folha como indicador de nitrogênio em cereais. Ciência Rural, Santa Maria, v. 31, n. 4, p. 715-722, 2001.

BARBIERI JÚNIOR, E. Características estruturais, teores de clorofila e suas relações com o nitrogênio foliar e a biomassa em capim-Tifton 85. 2009. 64 f. Dissertação (Mestrado em Zootecnia) - Universidade Federal Rural do Rio de Janeiro, Rio de Janeiro, 2009.

BORÉM, A.; CARNEIRO, J. E. S. A cultura. In: VIEIRA, C.; PAULA JÚNIOR, T. J. de; BORÉM, A. (Eds.). Feijão. Viçosa: UFV, 2006. p. 13-18.

BREDEMEIER, C.; MUNDSTOCK, C. M. Regulação da absorção e assimilação do nitrogênio nas plantas. Ciência Rural, Santa Maria, v. 30, n. 2, p. 365-372, 2000.

COMPANHIA NACIONAL DE ABASTECIMENTO (Conab). Feijão: séries históricas: área, produtividade e produção. 2011. Disponível em: < http://www.conab.gov. br>. Acesso em: 11 abr. 2011.

CURI, S.; CAMPELO JÚNIOR, J. H. Necessidades hídricas da cultura do feijoeiro (Phaseolus vulgaris L.) na baixada cuiabana. Revista Brasileira de Agrometeorologia, Santa Maria, v. 9, n. 1, p. 59-65, 2001.

DORCINVIL, R.; SOTOMAYOR-RAMÍREZ, D.; BEAVER, J. Agronomic performance of common bean (Phaseolus vulgaris L.) lines in an Oxisol. Field Crops Research, Amsterdam, v. 118, n. 3, p. 264-272, 2010.

EMPRESA BRASILEIRA DE PESQUISA AGROPECUÁRIA (Embrapa). Sistema brasileiro de classificação de solos. Rio de Janeiro: Embrapa/CNPSo, 2006.

EPSTEIN, E.; BLOOM, A. J. Nutrição e crescimento. In: EPSTEIN, E.; BLOOM, A. J. Nutrição mineral de plantas: 
princípios e perspectivas. 2. ed. Londrina: Planta, 2004. p. 251-284.

FAGERIA, N. K. Eficiência de uso de fósforo pelos genótipos de feijão. Revista Brasileira de Engenharia Agrícola e Ambiental, Campina Grande, v. 2, n. 2, p. 128131, 1998.

FAGERIA, N. K.; BALIGAR, V. C. Enhancing nitrogen use efficiency in crop plants. Advances in Agronomy, Newark, v. 88, n. 4, p. 97-185, 2005.

FAGERIA, N. D.; KLUTHCOUSKI, J. Metodologia para avaliação de cultivares de arroz e feijão para condições adversas de solo. Brasília, DF: Embrapa-CNPAF, 1980.

FALKER AUTOMAÇÃO AGRÍCOLA. Manual do medidor eletrônico de teor clorofila (ClorofiLOG/ CFL 1030). Porto Alegre: Falker Automação Agrícola, 2008.

FERREIRA, D. F. Sistemas de análises estatísticas para dados balanceados. Lavras: UFLa, 2003.

FIDELIS, R. R. et al. Eficiência quanto ao uso e resposta à aplicação de nitrogênio de cultivares de arroz em solos de terras altas no sul do Estado do Estado de Tocantins, safra 2007/2008. Bioscience Journal, Uberlândia, v. 28, n. 3, p. 432-438, 2012.

FRANCO, E. et al. Resposta do feijoeiro à aplicação de nitrogênio na semeadura e cobertura no sistema plantio direto. Acta Scientiarum Agronomy, Maringá, v. 30, n. 3, p. 427-434, 2008.

FURLANI, A. M. C.; BATAGLIA, O. C.; AZZINI, L. E. Variabilidade entre linhagens de arroz na absorção e utilização de potássio em solução nutritiva. Revista Brasileira de Ciência do Solo, Campinas, v. 10, n. 1, p. 135-141, 1986.

FURTINI, I. V. et al. Resposta diferencial de linhagens de feijoeiro ao nitrogênio. Ciência Rural, Santa Maria, v. 36, n. 6, p. 1696-1700, 2006.

LOPES, A. S.; BASTOS, A. R. R.; DAHER, E. Uso eficiente de fertilizantes nitrogenados e sulfatados na agricultura brasileira: uma visão do futuro. In: YAMADA, T.; STIPP, S. R.; VITTI, G. C. (Eds.). Nitrogênio e enxofre na agricultura brasileira. Piracicaba: INPI Brasil, 2007. p. 161-187.

PEEL, M. C.; FINLAYSON, B. L.; McMAHON, T. A. Update world map of the Köppen-Geiger climate classification. Hydrology and Earth System Sciences, Göttingen, v. 11, n. 5, p. 1633-1644, 2007.
PROCÓPIO, S. O. et al. Absorção e utilização do nitrogênio pelas culturas da soja e do feijão e por plantas daninhas. Planta Daninha, Viçosa, v. 22, n. 3, p. 365-374, 2004.

ROSOLEM, C. A.; MARUBAYASHI, O. M. Seja o doutor do seu feijoeiro. In: ROSOLEM, C. A.; MARUBAYASHI, O. M. Encarte de Informações Agronômicas, Piracicaba, n. 68, p. 1-16, dez. 1994.

SALGADO, F. H. M. et al. Comportamento de genótipos de feijão, no período da entressafra, no sul do Estado de Tocantins. Bioscience Journal, Uberlândia, v. 27, n. 1, p. 52-58, 2011.

SANT'ANA, E. V. P.; SANTOS, A. B. dos; SILVEIRA, P. da. Adubação nitrogenada na produtividade, leitura SPAD e teor de nitrogênio em folhas de feijoeiro. Pesquisa Agropecuária Tropical, Goiânia, v. 40, n. 4, p. 491-496, 2010.

SANT'ANA, E. V. P.; SANTOS, A. B. dos; SILVEIRA, P. M. da. Eficiência de uso de nitrogênio em cobertura pelo feijoeiro irrigado. Revista Brasileira de Engenharia Agrícola e Ambiental, Campina Grande, v. 15, n. 5, p. 458462, 2011.

SANTOS, A. B. dos; FAGERIA, N. K. Manejo do nitrogênio para eficiência de uso por cultivares de feijoeiro em várzea tropical. Pesquisa Agropecuária Brasileira, Brasília, DF, v. 42, n. 9, p. 1237-1248, 2007.

SILVA, C. C.; SILVEIRA, P. M. Influência de sistemas agrícolas na resposta do feijoeiro (Phaseolus vulgaris L.) irrigado à adubação nitrogenada em cobertura. Pesquisa Agropecuária Tropical, Goiânia, v. 30, n. 1, p. 86-96, 2000.

SILVA, L. S. et al. Resposta a doses de nitrogênio e avaliação do estado nutricional do arroz irrigado. Revista Brasileira de Agrociência, Pelotas, v. 13, n. 2, p. 189-194, 2007.

TAIZ, L.; ZEIGER, E. Fisiologia vegetal. 4. ed. Porto Alegre: Artmed, 2009.

THUNG, M. D. T.; OliVeIRA, I. P. de. Problemas abióticos que afetam a produção de feijoeiro e seus métodos de controle. Santo Antônio de Goiás: EmbrapaCNPAF, 1998. 